\title{
Enhancing Civic, Electoral, and Political Engagement Through International Student Inclusion
}

Adrienne McNally

New York Institute of Technology

\section{Author Note}

Adrienne McNally, International and Experiential Education, New York Institute of Technology.

Special thanks to Amy Bravo, Senior Director of International and Experiential Education at New York Institute of Technology, for conception of the Community Service Center at NYIT and for her significant contributions to experiential education at the college.

Correspondence regarding this article should be addressed to Adrienne McNally, Director, Experiential Education, International and Experiential Education, New York Institute of Technology, Northern Boulevard, P.O. Box 8000, Old Westbury, NY 11568. E-mail: amcnally@nyit.edu 


\begin{abstract}
International students are often overlooked in the typical civic engagement activities of colleges and universities. However, including international students in such activities adds significant value to an institution's efforts to increase students' civic, electoral, and political engagement. At New York Institute of Technology, international students make up $25 \%$ of the total student population, bringing a richness to the college's civic culture. This article discusses how international students have created and strengthened institutional initiatives designed to serve the public good. These initiatives include community service centers, Consultants for the Public Good, employee citizenship, voter registration and education, and Campus Conversations. The author also explores how these initiatives connect with A Crucible Moment, the National Task Force on Civic Learning and Democratic Engagement's 2012 call to action to "reclaim higher education's civic mission” through its framework for developing $21^{\text {st }}$-century civic skills and civic agency.
\end{abstract}

Keywords: civic engagement, experiential education, democracy, citizenship, global citizenship 
Too often, international students can feel disengaged from many civic engagement activities on campus, including voter registration drives and political discussions. Even in structured conversations concerning issues of race, religion, or ethnicity_dialogues to which international students may very well have unique experiences and alternative views to contribute-they may feel obligated to represent their country or religion as a token instead of adding their personal views based on their knowledge and experiences (Lee \& Rice, 2007). Students and staff at New York Institute of Technology (NYIT), however, have intentionally designed programs that capitalize on international student experiences, folding them into NYIT's culture and allowing the students to grow as student leaders. In light of today's political climate, the need for this empowerment is crucial and undeniable.

In recent years, many countries, including China, Hong Kong, Japan, the Philippines, Poland, Russia, Turkey, the United Kingdom, and the United States, have seen a rise in nationalism and have elected leaders who reflect this sentiment (Roth, 2017). This has affected U.S. colleges and universities in particular because the current administration has signed executive orders and supported legislation that negatively affects immigration (Jordan, 2017). Even though international students are not immigrants (most attend U.S. colleges or universities on F1 or J1 non-immigrant visas), the general message from the United States is that the country is not welcoming of foreign nationals. Some international students who come to the United States wish to remain after completing their studies. They can do this without immigrating for months or years depending on their major and the company for which they work. Yet, for these students, the messages of distrust they receive from United States leaders and policies those leaders support may encourage them to pursue their studies in another country. Not surprisingly, the number of international students in the United States is steadily declining (Saul, 2018).

In spite of these barriers, NYIT and other U.S. colleges and universities seek to support their international students by providing a welcoming environment, support services, and diverse programming. After all, it is the responsibility of the institution an international student attends to report the student's status to the federal government (U.S. Immigration and Customs Enforcement, 2018)—and one of the functions of the International and Experiential Education department at NYIT. 
Though a body of literature has focused on international student adjustment, little research has centered on what international students bring to their respective U.S. university communities. In this article, I discuss how NYIT has used experiential education programs and initiatives to develop students' civic skills and prepare them for democratic engagement. In particular, I explore how international students have broadened the definition of citizenship beyond nationality and detail their specific contributions to NYIT programs, which themselves expand and strengthen the college's intercultural learning community. I begin with a brief discussion of the theoretical background related to international student inclusion, the purpose of higher education, and relevant terminology. The majority of the article describes NYIT's programs and initiatives (including community service centers, campus conversations, voter registration and education, internships, service-learning, and alternative breaks) and how international students continue to move NYIT toward a more civically engaged campus.

\section{Theoretical Background and Literature Review}

Much of the scholarship around international students has focused on student adaptation to life in the United States and the culture of U.S. institutions of higher education. The literature has explored successful programming and the changes international students undertake to attain success, especially academic success, in the United States. For example, Andrade (2006) completed a detailed review of different strategies and programs to help international students adjust and to identify what universities can do to ease this adjustment and promote academic achievement. A later study by Telbis, Helgeson, and Kingsbury (2014) indicated that success, as defined by international students themselves, can be influenced positively by offering community events that promote social interactions. In particular, the researchers noted that these activities promote confidence in international students. Through my own work with international students participating in internships, I have observed a similar growth in confidence and increased involvement in professional activities and the U.S. workplace, as reported by students and their supervisors in evaluations during and after internship experiences.

NAFSA: Association of International Educators not only provides support for higher education staff who help ensure that international students maintain their status and engage fully with their college or university while in the United States, but also builds awareness of the value of international students. In the 2016-2017 
academic year, international students contributed $\$ 36.9$ billion to the U.S. economy and supported 450,000 jobs (NAFSA, n.d.). This dollar amount is equivalent to the GDP of a small country and should not be discounted simply because it represents a relatively small percentage of the U.S. GDP (World Bank, 2017). Beyond their economic value, international students benefit university communities because they "contribute an international perspective ...contribute ideas based on work experience and prepare domestic students for future encounters with diversity" (Andrade, 2006). This article therefore focuses on how international students enhance the NYIT community and help to broaden all students' understanding of community. To arrive at a definition of community, I start with the roots of higher education itself, particularly in the areas of service-learning and civic engagement.

Because I work in experiential education, I trace higher education's roots to John Dewey, who believed that democracy is practiced in all facets of life and that individuals learn by doing (Dewey, 1916). Dewey maintained that democracy requires the participation of its citizenry and that differences in individuals' ideas are essential to the growth of society. He also noted that a school is a society, or a "miniature community" (Dewey, 1916), providing a "unique environment" to develop and practice being an engaged citizen of a community. "Democracy is not political alone," Dewey held, but is "the idea of community life itself” (Dewey, 1927). Dewey's central tenets have echoed throughout the scholarly work of many others, especially concerning service-learning (Battistoni, 2000), since higher education is an ideal space to help students understand these ideas. Indeed, the responsibilities of colleges and universities to develop students into participants in democracy were further cemented in Educating for Democracy (Colby, Beaumont, Ehrlich, \& Corngold, 2007).

One can follow this conception of community and education's role in it to the development of service-learning, which began in the United States with Hull House and can be traced back to other early educators and thought leaders. Founded in Chicago by Jane Addams and Ellen Gates Starr, Hull House welcomed and housed new immigrants, who discussed community issues and worked to improve the lives of new citizens (Jane Addams Hull-House Museum, n.d.). For the purposes of this article, service-learning is defined as a pedagogy in which service is intertwined and inseparable from the course curriculum (Gardner \& Bartkus, 2014). Service activities comprise a "laboratory" for exploring course topics, and the service experiences inform assignments and lectures. Service-learning must 
always have a civic engagement component but is broad enough to include various forms of engagement, including advocacy, indirect service, and direct service. Service-learning also serves as a direct method of civic engagement.

However, international and domestic students experience service-learning differently. Green and Farazmand (2010) compared the outcomes for international and domestic students who had participated in a service-learning experience and found that "international students are more likely to realize (and influence the U.S. students of) the benefits of a service-learning project, e.g., increase learning (knowledge and skills), improved personal development-with learning by doing experiences” (p. 4). Students also noted that they looked forward to working in teams in the future. While the ability to work collaboratively does not specifically address civic engagement, it is a civic skill nevertheless.

In fact, the notion of civic skill expands when viewed through an experiential education lens. Green and Farazmand (2010) found that students learn to work collaboratively as part of service-learning. In the professional sphere, this is referred to as teamwork, requiring communication, adaptability, and flexibility. These skills, along with problem solving, are also civic skills (Battistoni, 2000). Related to service-learning and its impact on civic skills is Boyte's concept of "public work," whereby elementary to high school-aged students are coached to discuss issues in their community, define what they want using deliberative dialogue, develop solutions, and work with other citizens and community decision makers (i.e., legislators, mayors, etc.) to towards the desired change. This develops confidence in inexperienced people who can then effect change (Boyte, 2000). At NYIT, the Experiential Education office has found after surveying internship supervisors and interns that as students gain confidence they are more likely to take initiative, a skill the supervisors valued. My conversations with Boyte at Civic Learning and Democratic Engagement conferences helped bolster the idea of employee citizenship, the practice of citizenship in one's professional role, which is an essential component of the internship program at NYIT and will be discussed more thoroughly later in this article.

Through service-learning, internships, and other experiential education programs, the idea of citizenship expands beyond nationality to other communities, namely the college community. Students at NYIT are citizens of NYIT and therefore have rights afforded to them and responsibilities they must uphold. It is uncertain which students will stay to become U.S. citizens and which will not, but 
even so, it is the institution's duty to engage them, as temporary U.S. residents, in democratic society and allow them to change it.

\section{A Crucible Moment: Civic-Minded Students}

Another important component of developing international students' civic engagement on and off campus is its effort to directly address two specific elements of the emerging theory of change adapted from A Crucible Moment, a 2012 report that challenged educators "to advance a ... vision of college learning for all students ... with civic learning and democratic engagement an expected part of every student's college education” (National Task Force, 2012). The first is the civic ethos of a campus, which describes how the character of a campus is defined by its commitment to democratic values. At NYIT, civic ethos is determined by defining the variety of communities of which students are members: the NYIT campus, the local community, the communities in which students live and work, and the global community. Through NYIT's programs, students define the rights and responsibilities that citizens of each community have, and they practice civic skills such as communication, community problem solving, and debate around the ethics of their activities. The participants and the programs are embedded in every department and school at NYIT; thus, the participants—students, staff, and faculty alike-grow as active citizens, and that growth permeates the NYIT community and allows NYIT's civic ethos to deepen.

The next area of focus is civic agency, the ability of students to solve community problems together while considering and respecting individual differences. NYIT fosters this element through civic skill building. In each of NYIT's experiential education programs, students identify civic skills they developed, and they demonstrate how that development took place by providing examples. In particular, each semester the Internship Certificate Program is assessed in the following way:

- Students complete a learning agreement at the start of their internship in which they outline at least one learning objective and identify three (out of 12) skills that they want to develop during the internship.

- At the conclusion of the experience, students fill out an evaluation. Among other measures, students report on their most significant learning and skill development, which is then compared to the original learning agreement. 
- Supervisors complete midterm and endterm evaluations. Supervisors assess professional behaviors and skill needs (at the midterm) and development (at the endterm). These skills are compared to the students' evaluations to determine consistency.

Each spring, summer, and fall semester, between 70 and 200 students complete the internship program. In addition to the evaluation and assessment just discussed, the program includes orientation, coaching, and reflection.

The civic skills that students develop, as reported by the students and their supervisors, are indicators of civic agency. Students are asked to demonstrate how they developed at least one of the skills they identified in their post evaluation. The following are examples of the 72 student responses received after the spring 2017 semester:

- "When trying to make a patient's experience worthwhile the other volunteers and I thought of ways to make their hospital stay run smoothly through critical thinking and problem solving."

- "One of the skills I demonstrated was problem solving because my supervisor would present me with questions and ask what I think was best or what exercise I think the patient I should do next and then she would have me explain my reasoning. If my answer wasn't the best instead of simply telling me the answer, she would have me break the problem down and think about why a certain thing wouldn't work and explain the reasoning behind my answer."

- "Adaptability - I was extremely intimidated at first when I had to work with children with disabilities on horses. However, I kept calm during difficult times and took it step by step and grew to be comfortable working alongside them. I also took on challenges that I never thought I would take.”

- "My goal is intercultural communication. In the office, there was a diverse population of patients that spoke many different languages, and being exposed to this has helped me in having more patience and understanding."

- "Critical thinking and problem solving. Well, I am doing my internship program with MTA NYC subway contractor. We planned fan-plant, 
hydraulic pumps, CCTV camera for NYPD and lots of more. At our one site in subway we were install CCTV fixtures and run fiber with highvoltage cable. Here, high voltage creates noise in fiber cable and make distortion in results. So, after my discussion with my supervisor we separate fiber from high voltage cable and we solve it.”

- "Research: Sometimes in the office of online education there are questions that faculty have that may require additional research to find a solution and/or creating a document that will answer that question and show the faculty how to do it."

\section{Experiential Education Programs}

At NYIT, the International and Experiential Education department develops and manages experiential education programs, including service-learning, internships, community service centers, and alternative breaks. Similar programs at other colleges on Long Island are managed by different divisions and departments unique to each school. In recent years, programs with a strong civic engagement focus have come together under the Long Island Applied Learning Council, whose membership includes mostly higher education faculty and administrators interested in preparing their students for community engagement. At Adelphi University, for instance, community work is developed and coordinated through the Center for Student Involvement (see http://csi.adelphi.edu), while Hofstra houses a Center for Civic Engagement where students are trained and participate in activities from advocacy to public demonstration (see http://www.hofstra.edu/academics/colleges/hclas/cce). The State University of New York at Old Westbury focuses its students' community work on the first-year experience program, “Community Action, Learning and Leadership" (see http://www.oldwestbury.edu/call). Lastly, Stony Brook University’s wellrespected Career Center is the umbrella for the Community Service and Service Learning department (see http://www.stonybrook.edu/commcms/ communityservice). While experiential education at NYIT used to be housed under Career Services, similar to Stony Brook, it is now combined with international education to simplify international students' access to experiential education programs and to ensure inclusivity.

Much of NYIT's experiential education work in civic engagement is conducted through the Community Service Center (CSC). Each of NYIT's two 
New York campuses hosts a student-run CSC, overseen by experiential education staff. The CSC's mission is to engage NYIT students civically, politically, and electorally through volunteerism, voter engagement and education, fundraising, and knowledge/advocacy campaigns. The CSCs assist in running a number of programs to facilitate these activities, including Consultants for the Public Good, fundraising, voter registration, and Campus Conversations.

Consultants for the Public Good is a program in which students volunteer as pro bono consultants for nonprofit organizations. It is separate and unique from service-learning in that it is a volunteer program not connected to any course work, with no faculty oversight. Instead, staff members from International and Experiential Education oversee the program by accepting projects from nonprofit organizations and advertising the project to students. Ultimately, diverse teams (domestic and international, graduate and undergraduate learners of all ages) are selected by the nonprofits and the interested students. One student is designated as a leader of each volunteer project. NYIT students then use their expertise working on projects at community organizations seeking to improve public life. Because they are students, consultants often feel that they do not have much to contribute or that what they can contribute will not have much of an impact. However, this program has shown them that regardless of their prior work experience (or lack thereof), their grades, or their expertise in a particular field, they often know more than the organization seeking their assistance. As team members, they combine skills, share ideas, and test proposed solutions-all focused on meeting the same objective. These consulting projects represent high-impact education practices (Kuh, 2008), which lend themselves to different forms of learning that international students may find more effective, especially when lectures delivered in a language other than their native language can create additional barriers to learning and academic achievement (Andrade, 2006).

As a result of this work through Consultants for the Public Good, student participants gain greater confidence in themselves as professionals, and the experience has helped them work better in teams, as reported in student reflections and post-evaluations. Students have also reported improvements in their communication and planning skills, as well as their flexibility and adaptability. This provides an excellent foundation for international students new to the United States — who, because of federal regulations, cannot intern immediately— to build professional skills and resumes in preparation for their first internship. It also 
partners diverse groups of students on real-world projects, similar to those groups they would form in the global workplace or the community. Further, the nonprofit organizations teach consulting teams about problems in their respective communities and highlight the importance of the organizations in serving the public and filling gaps in the social safety net.

One example of a consulting project that student teams at NYIT undertook related to afterschool programs. In the afterschool programs, held at four public schools, small teams of NYIT students developed 10-week curricula on topics such as robotics and physics. Once a week over the 10 -week period, each consulting team met with students in the afterschool programs to deliver an interactive lesson. Consultants learned about working with youth from different backgrounds than their own and used their expertise as college students to teach lessons. In weekly reflections during the project, international students discussed the oftentimes stark differences between the concept of poverty in New York City and their home communities. International students shared their experiences being exposed to poverty, hunger (including starvation), and homelessness. In New York City, there are shelters and soup kitchens on which many poor can survive. This led to conversations in group planning meetings and reflections about government support systems and individualistic versus collectivist cultures. By sharing in the consulting experience together, international and domestic students can more readily engage in respectful dialogues that run counter to the current negative political climate (Lee \& Rice, 2007).

Another area of strong international student engagement at NYIT is voter registration. In 2016, three international students led the college's voter registration efforts, partnering with Turbovote (http://www.turbovote.org), the ALL IN Campus Democracy Challenge (http://www.allinchallenge.org), League of Women Voters, New York City Campaign Finance Board, and the Nassau County Board of Elections. Experiential Education staff also used the Institute for Democracy and Higher Education's (http://idhe.tufts.edu) action guide, Democracy Matters: Addressing Non-Statutory Barriers to College Student Voting, to inform voter registration and education programming. Voter registration occurs year-round at NYIT but is pushed most heavily during presidential election years. For some international students, voting and registering new voters is a special privilege because they do not have the ability to vote directly for leaders within their home countries. In 2016, over 300 NYIT students registered to vote (as tallied by 
Turbovote), and over 800 students participated in voter education events (calculated from sign-ins at events).

Voter engagement events at NYIT have brought together domestic and international students to discuss presidential candidates, issues of importance to students, and specific policies and how they could change under each of the candidates if elected. International students from the college's New York and global campuses (in Canada, China, and the United Arab Emirates) also participated in a mock election during which 218 students elected the candidate they would have chosen if eligible to vote. The Experiential Education office set up a Google Form to solicit votes for candidates, and on the online ballots, students were able to articulate why they had selected a particular candidate. The results were shared and discussed publicly at NYIT's “November $9^{\text {th }}$ : The Wednesday After” programs. The idea for these discussion programs was sparked through private conversations with Harry Boyte at the 2016 National Conference on Civic Learning and Democratic Engagement (see http://www.aascu.org/meetings/clde16).

During the "Wednesday After" discussions, participants talked about the implications of the 2016 presidential election as well as the results of the mock election, in which the 218 international students had participated. (Of these, 108 students were from India, 20 from China, and the rest from other countries, though mostly Saudi Arabia). Interestingly, students from China were more likely to choose Donald Trump, while students from India and the other countries selected Hillary Clinton. Some of the stated reasons for selecting Clinton included:

- "She promote rights for women and children."

- "For better environment of international students."

- "Her ethics on energy policy and job creation through renewable energy."

- "She would create a balance between capitalist and middle and lower strata of society.”

- "Because I believe in fighting for human rights, equality and I refuse to see the so called greatest country of all sinking and going back years. The wealthy people have enough money to live their lives, they want more, but they don't actually need them. What needs to happen is a better 
education system, accessible to every single person living in this country, a good healthcare plan that will make people to stop being so scared of visiting a hospital when they are sick etc. This country welcomed immigrants from all over the world for many years now, and maybe Clinton is not the best, but she is the least worst than the 2 candidates, she is more human oriented than business oriented and that's what America needs. I am not voting so my opinion doesn't really matter but I want to trust the American citizens.”

Reasons for selecting Donald Trump in the mock election included the following:

- "Firstly, he would have fair policies for the legal immigrants. Secondly, except his prosperous business, from the view of his children's achievements, he is capable to educate, supervise and provide all of them with equal opportunities no matter the gender and lead them to be successful, then the similar skills could be used to lead the country and the residents to be continuously great."

- "Also whatever the problem with Trump is yet he is showing the honest side of him and at least he is taking stand on illegal immigration which Obama never did and he know terrorism is a threat so he is promising countermeasures. Whereas Hilary is not a trustworthy person and her interest in politics is driven by just for her own sake.”

- “Trump will really do something to U.S. finance and economy."

- "He said, if he win he’s going to finish the ISIS."

- "Not a conventional politician.”

- “A businessman knows economy better and save U.S.A. Make people to work not dependent on government benefits and less burden on taxpayer."

These voter engagement activities illustrate two important aspects of community. First, citizenship takes many forms, and there are many levels of participation, all of which are valuable in a democratic society. Second, all citizens have a responsibility to contribute to their communities. Students can appreciate first-hand that they are citizens of NYIT, regardless of their nationality. As a group of NYIT citizens participating in these events and activities, students discussed national issues and how those issues affected them as students. They also discussed 
how the outcome of the 2016 election may affect life in their home countries. Students explored such issues in an environment where they could freely discuss their opinions - or change those opinions based on their personal experiences, the personal experiences of others, and/or their shared experiences as NYIT students. Generally, it is easier for students to talk about political matters when they use their personal experiences as a foundation (McCoy \& Scully, 2002). Even though candidates were selected largely along national lines, the reasons given for individual choices mirrored those of U.S. citizens, illustrating the many different conceptions of leading a country to global success.

The last CSC program worth noting here is Campus Conversations. Campus Conversations are modeled using deliberative dialogue (Nemenoff, 2008; November Fifth Coalition, 2008) and are held up to three times each semester on each of NYIT's New York campuses. The conversations explore issues of local, national, and global importance, including racism, access to opportunity, political elections, and environmental concerns. CSC staff members (who are students) are trained to run the conversations, including inviting students, faculty, and staff, selecting the topics, and facilitating the conversation. These conversations are not necessarily political; however, topics cover social issues, and discussions often delve into what governments could do to address the social problems.

Over the last four years, international students have led these Campus Conversations. They are trained in deliberative dialogue (McCoy \& Scully, 2002), although the process does not necessarily reach the final stage, during which solutions to community problems are presented to local officials. The conversations are conducted in the spirit of "open-minded inquiry," which invites diverse views, models civility, and enlists other campus organizations for participation (Colby et al., 2007). For instance, CSC staff members have recruited students from the Muslim Student Association to host one conversation per semester and have also included students from NYIT's global campuses in conversations. By participating in Campus Conversations, students learn civic skills in communication, empathy, ethics, and debate. The conversations force participants to explore their assumptions, recognize the differences between fact and feeling, and respect others' points of view. Most importantly, the conversations highlight the complexity of community problems and the challenges of solving them collaboratively (Colby et al., 2007; McCoy \& Scully, 2002). 
The International and Experiential Education department at NYIT also manages alternative break trips. In 2017, 26 international and domestic students participated in two trips to engage in housing and education issues in the Dominican Republic and Nicaragua. The teams comprised domestic and international students, a student leader, and a staff and/or faculty leader. The intensive nature of service abroad lends itself well to student transformation; this year, the office enhanced these experiences by requiring all students to complete a course in which they came together through orientations, assignments, and discussions before and after the trip to delve deeply into the socioeconomic and political histories and current states of the countries they visited and of the United States.

During each trip, students worked alongside community members to build homes and work with community youth. In this way, they learned more fully about the culture of and the issues impacting their host communities. Students could then compare what they experienced "on the ground" with what they had discussed and written about in the preceding course. For example, in their final written reflections students wrote:

- "I want to be an agent of change. The change I'm leaning towards doesn't have to do with other countries however, I want to start right here."

- "I feel obligated to help anyone less fortunate than I am."

- "My mission is not over. I started helping people locally. What I thought wasn't my business at all, became one of my first priorities."

Additionally, during alternative break, international students share their experiences coming to the United States and experiencing U.S. culture for the first time. In this way, during alternative break trip, international students provide guidance and support to domestic students who have never left the United States. Students also compare and contrast their perspectives on poverty, education, and how governments and global citizens solve problems.

Finally, through NYIT's academic internship program, students focus on employee citizenship - that is, becoming a contributing member of one's professional community. This concept relates to the role of the citizen professional, who serves as a resource to the community, and works alongside them to solve public problems (Boyte, Civic Education as a Craft, Not a Program, 2000) (Boyte, 
The Citizen Solution, 2008). NYIT's Experiential Education programs focus on developing civic skills in the professional sphere and then talking about how those skills can be applied to other communities to which the student belongs.

NYIT's Experiential Education programs divide employee citizenship into four areas: awareness, rights, responsibilities, and engagement. Each of these areas is defined through professional work. For example, awareness describes the skills, experience, and knowledge that student interns offer the industry and company for which they work. Engagement relates to how students can become more active in their respective fields by joining professional organizations and reading publications in their fields. Also, through advisors' individual coaching, group meetings, and reflections, students learn how to develop civic skills and focus on engaging in activities they can use in their home communities to effect change. These civic skills include: verbal communication, written communication, critical thinking/problem solving, organization/planning, research, intercultural communication, intergenerational communication, adaptability, time management, flexibility, technology, and leadership. Experiential Education staff members coach students to help them identify these skills and learn how they can be practiced at an internship or in a service project (i.e., service-learning, Consultants for the Public Good, or alternative break). For example, during the orientation for the Internship Certificate Program, Experiential Education staff describe the concept of employee citizenship and provide students with a table listing a number of engagement activities and the corresponding skills they would develop by participating in those activities (see 
INTERNATIONAL STUDENT INCLUSION

Table 1). 
Table 1

Employee Citizenship Activities and Civic Skills

Activity Civic Skills Developed

Participate in community projects your company sponsors

Be knowledgeable about your company and industry

Identify needs within your company and addressing them

Help without being asked

Follow the rules and question those that don't seem ethical

Actively strengthen the company's image

Understand your company's role in not only their industry, but the community in which they are located-corporate social responsibility

Give back to your industry by writing white papers/blogs, participate in discussions and share your knowledge

Find companies that share your personal/ professional values

Speak up when you see unethical behavior in the workplace
Intercultural, intergenerational communication

Research, critical thinking

Critical thinking/problem solving, leadership

Leadership, organization/planning

Critical thinking/problem solving, communication

Leadership

Research, critical thinking

Research, flexibility, adaptability

Problem solving, communication, leadership 
Do what ought to be done rather than what is easiest/customary

Think critically and asking questions

Join the professional organization associated with your major or industry

Be honest and trustworthy

Do not engage in gossip; uplift others instead of tearing them down

Recognize that you do not work in isolation; collaborate with others to reach common goals

Have the courage to make suggestions that might benefit the company and the community it serves
Leadership, organization/planning, time management

Critical thinking, communication, adaptability

Time management, communication

Leadership, communication

Communication, leadership

Flexibility, adaptability, leadership, problem solving

Communication, leadership

To explore the topic of civic-minded students, it is worth turning again to $A$ Crucible Moment (National Task Force, 2012). Experiential Education staff take particular interest in the dimensions of civic learning and democratic engagement in the "Framework for Twenty-First-Century Civic Learning and Democratic Engagement," outlined in A Crucible Moment. This framework identifies four areas that appear consistently when measuring students' learning outcomes related to academic programs that emphasize civic learning. As the authors suggest in $A$ Crucible Moment, this framework must be more clearly defined by the setting in which it is used. What follows are ways that NYIT is applying this framework in the areas of knowledge, skills, values, and collective action.

In the area of knowledge, NYIT focuses on the concept of identity and sharing with others personal knowledge gained from students' cultural and national backgrounds. Even what may be considered factual information can be interpreted differently by different groups because of media coverage and the biases of the 
INTERNATIONAL STUDENT INCLUSION

groups with which students identify. Such differences can seem suddenly stark when students who grew up in different countries come together and begin exploring issues together. More specific examples are outlined in 
INTERNATIONAL STUDENT INCLUSION

Table 2. 
Table 2

Knowledge Framework Area

\section{Framework Item}

Historical and societal movements and their international implications

Understanding one's sources of identity and their influence on civic values, assumptions, and responsibilities to a wider public

Knowledge of the diverse cultures, histories, values, and contestations that have shaped U.S. and other world societies

Exposure to multiple religious traditions and to alternative views about the relation between religion and government

\section{Examples at NYIT}

International students contribute personal perspectives to events and changes that U.S. students have only read about in texts.

Cultural differences can have a large impact on how citizens view their role in their communities. International students can share their perspectives on citizenship on how they may have changed since being immersed in U.S. culture.

International and domestic students can lay as a foundation their cultural and historical identities as personal stories to highlight their societies beyond what they read or talk about with members of their own countries.

Clearly, international students increase the chances of domestic students meeting people of other traditions.

The next framework area relates to skills. This area is particularly suited to higher education, where students work to gain skills to move them into the next phase of their life-namely, work or more education. At NYIT, students are careerfocused and respond well to opportunities to develop professional skills. Experiential education programs help students to translate these professional skills into community problem solving skills. Table 3 highlights a few examples. 
Table 3

Skills Framework Area

\section{Framework Item}

Gathering and evaluating multiple sources of evidence

\section{Examples at NYIT}

Through verbal and written interaction, students learn to incorporate the personal stories of their fellow students into other sources they use to get information. They can also learn to better evaluate international publications using students' insight from their experiences within the countries where those publications originated.

Seeking, engaging, and being informed by Through alternative breaks and multiple perspectives internships, Experiential Education staff ask participants to talk openly with the community members and colleagues to practice in a low-risk environment how to get information from others.

Deliberation and bridge building across differences
Campus conversations and group service projects exemplify how international students and domestic students work together to assess solutions, listen to one another, and learn to compromise among different opinions to solve problems

The third framework area, values, can seem the most challenging to instill in students. After all, before coming to college, they have already developed strong values as a result of their personal experiences. The Experiential Education office seeks to name values, including those that A Crucible Moment employs (see

Table 4), and to coach students in understanding how those values apply to them and their communities. 
Table 4

Values Framework Area

Framework Item

Open-Mindedness

Tolerance

Responsibility to a Larger Good

\section{Examples at NYIT}

Simply by interacting with people who may have been seen as "other," international and domestic students are able to characterize each other beyond stereotypes.

Through open discussion, group service projects, and interning together, domestic and international students develop tolerance for people within other groups to see individuals in all their communities.

Perhaps in this area, international students can make the biggest difference. Many countries outside of the U.S. have a more collectivist society than our individualist society. We have found that international students can be strong proponents for how acting as one group can create change and how careful government intervention with a focus on those most in need can benefit society as a whole.

The three previous framework areas can come together in the fourth: collective action. In this area students put their civic skills to work. They use the values and knowledge they have gained to develop a plan of action to advocate for and create change within their communities. International students can be of particular use to U.S. and domestic students in their deeper understanding of how groups of people can influence those in power to implement changes that benefit the community (see 
INTERNATIONAL STUDENT INCLUSION

Table 5). 
Table 5

Collective Action Framework Area

Framework Item Examples at NYIT

Navigation of political systems and Because, as this report highlighted, civic processes, both formal and informal education in the US is lacking, we often find that international and domestic students learn to navigate US political systems together. As a group they learn how to contact representatives, how the electoral system works, and how to ensure that their voices are being heard. International students learn their value as citizens of the town, county, and state, while they are here, and feel empowered to contact representatives as well.

Compromise, civility, and mutual respect Through campus conversations, service projects, and internships, students work through problems together. They learn to respect one another as members of our community and stand up for one another's rights in while holding each other accountable for their responsibilities as citizens.

A Crucible Moment fills in the "gaps" within the historical mission of higher education in an effort to understand how to put civic learning into practice. The authors provide ways to talk about teaching civic engagement. Also, the Association of American Colleges and Universities (n.d.) and educators in the United States developed VALUE rubrics to assess learning outcomes in 16 areas, including critical thinking, civic knowledge and engagement, and global learning, among others. The 16 areas include outcomes that "students need for success in work, citizenship, and life" as well as proficienies that the National Institute for Learning Outcomes Assessment (see http://www.degreeprofile.org) deem necessary for students graduating from college with associate, bachelor's, and 
master's degrees to attain. Higher education administrators and faculty can develop and evaluate programs that center on developing students into citizens while enriching the institutional community.

\section{Conclusion}

Through NYIT's experiential education programs, the college seeks to develop students' civic skills through experience- - heeding Dewey's call to prepare students for participation in democracy. The Experiential Education programs extend the notions of community and citizenship to encompass all communitiesschool, work, the community students grew up in, and the community they live in now-so that educators can listen to and value the voices of all NYIT citizens. In this way, international students are incorporated more fully into the campus culture, increase their confidence, and, as research suggests, attain better academic outcomes.

In turn, institutions can greatly enhance their efforts to graduate civically engaged citizens by incorporating international students' experiences and celebrating their strengths. This deliberate recognition and inclusion is critical, especially now as communities and nations face divisions along lines of religion, race, nationality, and ethnic background. While increasing international student engagement certainly adds a multicultural component to an institution's culture and helps the institution meet its mission of preparing citizens for engagement in their communities, it also helps to combat the cynical and unwelcoming messages of the current political climate. Indeed, incorporating international students' expertise and deliberately coaching them in the acquisition of civic skills is essential for all students as they work toward becoming actively engaged participants in their communities. 


\section{References}

Andrade, M. S. (2006). International students in English-speaking universities: Adjustment factors. Journal of Research in International Education, 5(2), 131-154.

Association of American Colleges and Universities. (n.d.). VALUE rubric development project. Retrieved from www.aacu.org/value/rubrics

Battistoni, R. M. (2000). Service learning and civic education. In S. Mann \& J. Patrick (Eds.), Education for civic engagement in democracy: Service learning and other promising practices (pp. 29-44). Bloomington, IN: ERIC Clearinghouse for Social Studies.

Boyte, H. C. (2000). Civic education as a craft, not a program. In S. Mann \& J. Patrick (Eds.), Education for civic engagement in democracy: Service learning and other promising practices (pp. 61-72). Bloomington, IN: ERIC Clearinghouse for Social Studies.

Boyte, H. C. (2008). The citizen solution. St. Paul, MN: Minnesota Historical Society Press.

Colby, A., Beaumont, E., Ehrlich, T., \& Corngold, J. (2007). Educating for democracy. San Francisco: Jossey-Bass.

Dewey, J. (1916). Democracy and education. New York: Macmillan.

Dewey, J. (1927). The public and its problems. New York: Henry Holt and Company.

Gardner, P., \& Bartkus, K. R. (2014). What's in a name? A reference guide to workeducation experiences. Asia-Pacific Journal of Cooperative Education, 15(1), 37-54.

Green, R. D., \& Farazmand, F. A. (2010). Learning by doing: A comparative study of U.S. and international students. In MMA Fall Educators' Conference Proceedings (pp. 1-6). Retrieved from http://www.mmaglobal.org/publications/Proceedings/2010-MMA-FallEducators-Conference-Proceedings.pdf

Jane Addams Hull-House Museum. (n.d.). About the museum. Retrieved from https://www.hullhousemuseum.org/about-the-museum/ 
Jordan, M. (2017, December 23). Ninth Circuit judges rule against latest travel ban. New York Times, A17.

Kuh, G. D. (2008). High-impact educational practices: What they are, who has access to them, and why they matter. Washington, DC: Association of American Colleges and Universities.

Lee, J. J., \& Rice, C. (2007). Welcome to America? International student perceptions of discrimination. Higher Education, 53(3), 381-409.

McCoy, M. L., \& Scully, P. L. (2002). Deliberative dialogue to expand civic engagement: What kind of talk does democracy need? National Civic Review, 91(2), 117-135.

NAFSA. (n.d.). NAFSA international student economic value tool. Retrieved from NAFSA http://www.nafsa.org/Policy_and_Advocacy/Policy_Resources/Policy_Tre nds_and_Data/NAFSA_International_Student_Economic_Value_Tool/

National Task Force on Civic Learning and Democratic Engagement. (2012). A crucible moment: College learning and democracy's future. Washington, DC: Association of American Colleges and Universities.

Nemenoff, B. (2008). National collegiate dialogue. Retrieved from http://www.aascu.org/programs/ADP/publications/CollegiateDialogue/

November Fifth Coalition and American Democracy Project. (2008). Campus Conversation Toolkit. Retrieved from http://www.aascu.org/programs/ADP/publications/ CampusToolkit/

Roth, K. (2017). The dangerous rise of populism: Global attachs on human rights values. New York: Human Rights Watch.

Saul, S. (2018, January 3). Scrutiny on foreigners crimps rich vein of college revenue. New York Times, A1.

Telbis, N. M., Helgeson, L., \& Kingsbury, C. (2014). International students' confidence and academic success. Journal of International Students, 4(4), 330-341. 
U.S. Immigration and Customs Enforcement. (2018). SEVIS reporting requirements for designated school officials. Retrieved from https://www.ice.gov/sevis/dso-requirements

World Bank. (2017). GDP ranking. Retrieved from https://data.worldbank.org/data-catalog/GDP-ranking-table 


\section{Author Biography}

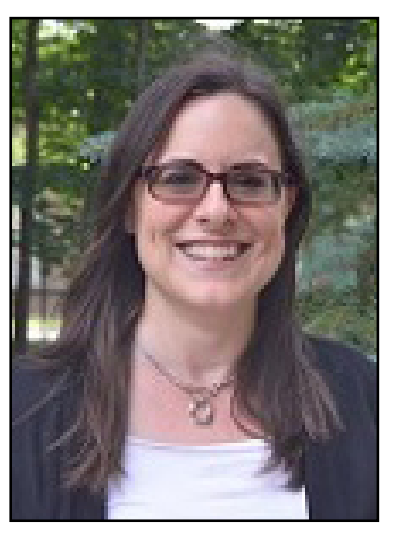

While a doctoral candidate in engineering, Adrienne McNally left her career and degree pursuit in engineering to level the playing field for female engineers. Due to her six internships as an undergraduate and research experience in graduate school, higher education was the forum in which she felt she could affect the most change in this area. She entered NYIT as a coordinator for Student Employment and was promoted to Director of Experiential Education. In this role, she and her supervisor developed a variety of experiential programs that bridge career and civic development. Among them is a nationally recognized centralized internship program, which prepares students for the world of work and for their roles as actively engaged public problem solvers.

At NYIT, McNally develops and assess the outcomes of the centralized Internship Certificate Program, including its foundation in civic engagement, delivered through the concept of employee citizenship. She works with faculty on developing and accessing service-learning courses, oversees the institution's Community Service Center, and has recently taken a leadership role in the newly formed department of International and Experiential Education. McNally instructs online undergraduate and graduate internship courses in computer science and electrical and computer engineering.

Adrienne has shared her work with civic education and internship programs as a keynote speaker at NYSCEEA in September 2016; as a speaker at NASPA in June 2016 and 2015; LICSPA in February 2015; CEIA April 2013, March 2010, and April 2009; and led InternBridge webinars in August 2012 and February 2010. She has a B.S. in Industrial Engineering from Northeastern University and an M.S. in Management Science from Lehigh University. 